\title{
ОСОБЕННОСТИ ЛЕКСИКО-ГРАММАТИЧЕСКОГО СТРОЯ ЯЗЫКА СПЕЦИАЛЬНОСТИ И ЕГО ОСВОЕНИЕ КИТАЙСКИМИ УЧАЩИМИСЯ
}

\author{
Доцент, к.ф.н. Мусабекова Н. Ч. \\ Азербайджанская Республика, Баку, Азербайджанский государственный университет нефти и \\ промыиленности
}

DOI: https://doi.org/10.31435/rsglobal_ws/31012020/6909

\begin{abstract}
ARTICLE INFO
Received: 21 November 2019

Accepted: 17 January 2020

Published: 31 January 2020

\section{KEYWORDS}

scientific style, grammar categories,

Russian and Chinese.

ABSTRACT

The study was aimed to consider the features of the lexical and grammatical structure of the scientific style of the Russian language and learning difficulties for the Chinese students at the early academic study. Drawing parallels between grammar categories of Russian and Chinese Author clarifies all the reasons for the emergence of the students' difficulties, analyses their mistakes and offers different types of exercises, aimed at eliminating all the mistakes of students. Author dwells on the major grammar categories of the Russian language and explains how difficult it is for foreigners to accept them. She provides examples of grammar categories which are difficult to study, such as, Participle I, II; Adverbial Participle; Active/Passive Constructions and etc. Author pays attention to the issues of word formation, word order in the Russian sentences. She offers different kind of tasks which are intended for the development of communication skills of the Chinese.
\end{abstract}

Citation: Мусабекова Н. Ч. (2020) Osobennosti Leksiko-Grammaticheskogo Stroya Yazyka Special'nosti i Ego Osvoenie Kitajskimi Uchashchimisya. World Science. 1(53), Vol.3. doi: 10.31435/rsglobal_ws/31012020/6909

Copyright: (C) 2020 Мусабекова Н. Ч. This is an open-access article distributed under the terms of the Creative Commons Attribution License (CC BY). The use, distribution or reproduction in other forums is permitted, provided the original author(s) or licensor are credited and that the original publication in this journal is cited, in accordance with accepted academic practice. No use, distribution or reproduction is permitted which does not comply with these terms.

Введение. Грамматическая структура любого языка отражает различные стороны мироощущения и мировосприятия того или иного народа. "Смысловое содержание, закодированное в единицах языка, грамматических категориях, отражает специфическое преломление действительности в языковом сознании носителей той или иной лингвокультуры." [1] Эти речевые представления о мире являются субъективными образами конкретной этнической группы, поэтому понятия о разных предметах, явлениях природы, научных категориях своеобразно трансформируются в разных языках мира. Сказанное в полной мере относится и к языковым системам русского и китайского языков. Когнитивная система миропонимания русского человека закодирована в грамматических категориях русского языка, в китайском же языке те же смысловые категории выражаются на лексическом уровне в силу изолированного характера языка китайцев. Столь большие различия в грамматическом устройстве этих двух языков приводят к многочисленным ошибкам в речи учащихся как на уровне нейтрального стиля речи русского языка, так и научного стиля, в особенности, на начальном этапе обучения.

Задачей преподавателя русского языка, обучающего студентов-иностранцев азам языка будущей специальности, является формирование стимулирующих профессиональных мотивов и лингвокоммуникативной компетенции учащегося. Работая с указанным контингентом, следует уделять большое внимание жанрам письменной речи, таким как: план, тезисы, рефератконспект, эссе, доклад, аннотация и др., - но обучение этим видам работ начинается с изучения особенностей структуры языка и содержания научного текста. И на этом этапе работы преподавателю предстоит познакомить студентов с лексико-грамматическими особенностями научного стиля речи русского языка. 
Результаты исследований. В настоящей статье мы остановимся на трудностях освоения лексико-грамматических конструкций китайскими студентами нефтехимического профиля на предвузовском этапе подготовки. Нам хотелось бы озвучить основные лексикограмматические категории, освоение которых вызывает наибольшие трудности у китайских студентов в силу особенностей их родного языка, а также наметить пути устранения возникающих языковых проблем (рекомендовать конкретные типы заданий).

Знакомство с научным стилем, стилем будущей специальности, начинается с работы над научным текстом, работы над используемой в тексте лексикой и терминологией, терминологическими конструкциями. В рамках работы над лексикой необходимо развивать в студентах умение выделять [2] корень слова, путем формального анализа слов научиться определять принадлежность слова к той или иной части речи, научиться образовыватв новые слова с помощью предложенных аффиксов (например, прилагательные - с помощью суффиксов -енн-, -н-,-ическ- и др.) Выполнение подобного рода заданий представляет большую трудность для китайских студентов, так как русский язык обладает многообразием типов словообразовательных моделей, в китайском же словообразование сводится к образованию слов или путем сложения двух(реже - трех или четырех) односложных слов , или путем повтора одного и того же односложного слова, или путем присоединения к односложному слову специального грамматического элемента - суффикса или префикса (их количество весьма ограничено). Тем важнее указать на имеющиеся в языках корреляты суффиксов. Например, рус. суф. сущ. -ость, -ность, -мость и -есть, обозначающим свойства, соответствует суф.- xìng (gémìngxìng револющионность, zŭzhīxìng организованность); сущ. на -ация, -фикация и -ция, обозначающим процесс осуществления действия, в китайском соответствует - huà (gōngyèhuà индустриализация, jítǐhuà коллективизация); суф. сущ. -meль, обозначающему лицо-деятеля, обычно соответствует суф. - jī̄̄ (sīxiăngjiā мыслитель, zuòjiā nисатель) и т.д. [4,7] Затем студентам можно предложить

1. образовать по моделям новые слова "действие $\rightarrow$ проиесс" (взаимодействовать $\rightarrow$ взаимодействие; ускорять $\rightarrow$ ускорение; описать $\rightarrow$ описание...), а после трансформировать СС с глаголами "действия" на СС "процесс + 2. P.n. чего?" (тело движется $\rightarrow$ движение чего? $\rightarrow$ движение тела);

2. образовать по моделям новые слова "действие $\rightarrow$ метод получения вещеетва" (разлаГать + 4.B.n.что? вещество $\rightarrow$ разлоЖение +2 P.n.чего? вещества; перегонять + 4.B.n.чmo? нефть $\rightarrow$ перегонка +2 P.n.чего? нефти; обжигать + 4.B.n.что? глину $\rightarrow$ обжиг + 2P.n.чего?глины...), а затем выполнить ряд заданий. Например:

а) Преобразуйте данные предложения по модели. Модель: Металл плавяm. $\rightarrow$ Металл подвергают плавке.

б) Используя информацию 2 предложений, составьте 1 предложение, в котором бы указывался метод получения вещества. Модель: На воздухе прокаливают железный колчедан $(\mathrm{FeS})$. Получают диоксид серы $\left(\mathrm{SO}_{2}\right) . \rightarrow$ Диоксид серы получают путём (с помощью, методом, способом) прокаливания на воздухе железного колчедана.

3. образовать по моделям новые слова "качество $\rightarrow$ свойство" (пластичный $\rightarrow$ пластичность, горючий $\rightarrow$ горючесть...), а затем использовать их при трансформации предложений по заданным моделям. Например:

a) Марганец - хрупкий металл. $\rightarrow$ Марганец характеризуется (обладает, отличается) хрупкостью.

б) Железо - .... металл. Оно отличается... и .... (ковкий, ковкость; пластичный, пластичность) $\rightarrow$ Железо - пластичный (ковкий) металл. Оно отличается ковкостью и пластичностью.)

4. образовать краткие формы прилагательных и причастий от полных форм по моделям (твёрдый $\rightarrow$ твёрд, тверда...; активный $\rightarrow$ активЕн, активна...; лёгкий $\rightarrow$ лёгОк, легка...), а затем вставить необходимые формы в предложения. Например: Фтор - химически ... вещество. Свободный фтор очень...(активный, активен) $\rightarrow$ Фтор - химически активное вещество. Свободный фтор очень активен.

5. образовать сравнительную степень прилагательных по модели (активный $\rightarrow$ активнее $\rightarrow$ более (менее) активный.....; мягКий $\rightarrow$ мягЧе $\rightarrow$ более (менее) мягКий ; твёрДый $\rightarrow$ твёрЖе $\rightarrow$ более (менее) твёрДый; ....), а затем выполнить ряд задания. Например: 
а) Сравните вещества. Ответьте на вопросы. Модель: Какой газ легче: водород или кислород? $\rightarrow$ Водород легче кислорода. Кислород тяжелее, чем водород.

б) Сравните вещества по степени обладания качеством. Модель: Натрий и золото - по мягкости. $\rightarrow$ Натрий мягче, чем золото.

6. указать слова, от которых образованы данные сложные слова: месторождение от " место, рождать(ся)", рельефообразование от " рельеф, образовать"; гипсо-соленосный (пласт) от "гипс, соль, носить ", гидроциклон от "гидро-, ияиклон", каменноугольный (пласт) от "камень, уголь" и т.д.

Здесь были представлены лишь некоторые типы заданий, позволяющие формировать и развивать языковую догадку студентов, увеличивать запас специальных слов и языковых конструкций, так необходимых для выражения собственных высказываний.

Работа над лексикой научного текста предполагает выполнение и другого рода заданий. Так,

1. используя данные Таблицы словообразовательных элементов греческого и латинского происхождения, определите значения следующих слов: деформация, регрессия, кристаллография, геотектоника.... В случае затруднения уточните лексические значения этих слов по словарю;

2. соотнесите научные понятия с их характеристикой:

1. миграция а) образование углеводородов;

2. аккумуляция б) перемещцение углеводородов в земной коре;

3. генерация $\quad$ в) процесс накопления нефти и газа в ловушках;

3. - подберите антонимы к словам: адекватный -..., макропланктон -..., высокогорный- ...., моновариантный - ......;

- замените выделенные в предложениях слова на антонимы (выберите нужные слова из прилагаемого списка): На раннем этапе своего развития Земля была сравнительно холодной и тектонически пассивной планетой.

4. - подберите синонимы к словам: ассимилящия - ..., дивергенция - ...;

- установите соответствие между словами в колонках:
1. мощность отложений
а) колебание;
2. амплитуда прогибания
б) определение;
3. идентификачия типа осадочного бассейна
в) толичина;

- замените выделенные в предложениях слова на синонимичные (выберите нужные слова из прилагаемого списка): Из позвоночных животных в морях каменноугольного периода доминирующее положение занимали рыбы.

5. ознакомьтесь с характеристикой некоторых понятий:

факторы (какие?): геотермические, тектонические, гидрогеологические...;

осадочный (что?): бассейн, чехол; осадочная порода, толща и др.

Отсутствие в китайском языке большинства грамматических категорий, свойственных русской языковой системе (категории рода, падежа, лица, числа, наклонения, степени сравнения (у прилагательных, наречий), и несоответствие понятия о частях речи в русском и китайском языках (так, прилагательное в китайском языке может указывать не только на "признак предмета" (как в русском языке), но и на "признак действия"; русские глагольные категории "причастие" и "деепричастие" в китайском отсутствуют вообще и т.д.) приводят к появлению таких ошибок, как: Тело движется по прямая линия.(вместо: Тело движется по прямой линии.) Мой болезнь с вашим болезнем совсем одинаковы. (вместо: Наши с вами болезни одинаковыл.) Я часто встречаю с друзьям. (вместо: Я часто встречаюсь с друзьями.) Этот карандаш короткий-короткий, чем тот карандаш. (вместо: Этот карандаш короче, чем тот карандаш.) Объем газа, добываюший в Азербайджане, растет год от года. (вместо: Объем газа, добываемого в Азербайджане, растет год от года.)

К наиболее сложным лексико-грамматическим конструкциям, вызывающим проблемы в усвоении, можно отнести причастные / деепричастные обороты, конструкции с активными / пассивными причастиями, студентам трудно удаются задания на трансформацию деепричастных и причастных оборотов в СПП с придаточными разной лексической направленности (и наоборот).

Формально причастия и деепричастия отсутствуют в китайском языке, но их можно переводить несколькими языковыми средствами, имеющими разную степень эквивалентности. Выбор средства должен быть направлен на достижение переводческой эквивалентности. 
Главное, что надо учитывать при переводе, - это необходимость ориентироваться на роль причастий / деепричастий в структуре предложения и их взаимоотношения с субъектом и предикатом, а также со второстепенными членами предложения; анализировать их семантику. "Для достижения эквивалентности при переводе безэквивалентной грамматической единицы целесообразно использовать трансформационно-семантическую модель перевода, поскольку именно она предлагает пути достижения эквивалентности путем доступных трансформаций исходных грамматических структур" [5, 175]

Для развития навыков образования и использования в речи причастных (I) и деenрuчастных (II) конструкций можно предложить выполнение следующих заданий:

I.1. Образуйте причастия от данных глаголов по моделям: (действительные причастия) НСВ: делать $\rightarrow$ (они)делают $\rightarrow$ делающй̆ (делающая, делающе, делающие), строить $\rightarrow$ (они) строят $\rightarrow$ строящий (строящая...); использовать $\rightarrow$ используют $\rightarrow$ использующий $(.$.$) ,$ анализировать $\rightarrow$ анализируют $\rightarrow$ анализирующий $(\ldots)$; СВ: сделать $\rightarrow($ он) сделал $\rightarrow$ сделавщий (сделавшая, сделавшее, сделавщие), нести $\rightarrow$ (он) нёс $\rightarrow$ нёсший (нёсшая, нёсшее, несшие); (страдательные причастия) НСВ: изменять $\rightarrow$ (мы) изменяем $\rightarrow$ изменяемый (изменяемая, изменяемое, изменяемые), любить $\rightarrow$ (мы) любим $\rightarrow$ любимый (..); использовать $\rightarrow$ используешь $\rightarrow$ используемый $(. .$.$) , анализировать \rightarrow$ анализируешь $\rightarrow$ анализируемый (...); СВ: сделать $\rightarrow$ (он) сделал $\rightarrow$ сделанный (сделанная, сделанное, сделанные), устроить $\rightarrow$ (он) устроил $\rightarrow$ устроенный $(. .$.$) , принести \rightarrow($ он) принёс $\rightarrow$ принесённый (...) и т.д.; составьте с образованными причастиями СС (или ПП), типа: студент, делающий домашнее задание; студент, сделавший домашнее задание; прибор, используемый в эксперименте (ученым); прибор, использованный в эксперименте (ученым) и т.д.;

I.2. Замените предложения с причастными оборотами на конструкции СП с союзным словом "который". Модель: Углекислый газ является основным веществом, вызывающиим эффект глобального потепления. $\rightarrow$ Углекислый газ является основным веществом, которое вызывает эффект глобального потепления.

I.3. Замените конструкции СП с союзным словом "который" на причастные обороты. Модель: Нефть может заменить близкая ей по свойствам смола, которую получают при переработке горючих сланцев. $\rightarrow$ Нефть может заменить близкая ей по свойствам смола, получаемая при переработке горючих сланцев.

I.4. Вставьте в предложения активные или пассивные причастия, предварительно образованные от данных в скобках глаголов. Модель: Начало подземной выработки, .... к поверхности или к другой выработке, называется устьем. (примыкать) $\rightarrow$ Начало подземной выработки, примыкающей к поверхности или к другой выработке, называется устьем.

I.5. Вставьте в предложения полные или краткие причастия, предварительно образовав их от данных в скобках глаголов. Модель: ....закономерности использованы для прогноза нефтегазоносности. На ряде участков .... отставание от проектного уровня закачки воды. $($ отметить $) \rightarrow$ Отмеченные закономерности использованы для прогноза нефтегазоносности. На ряде участков отмечено отставание от проектного уровня закачки воды.

I.6. С помощью кратких причастий преобразуйте задачи исследования в его результаты. Модель: Выявление закономерностей в динамике запасов нефти. $\rightarrow$ В динамике запасов нефти выявлены закономерности.

I.7. Из двух ПП составьте одно СП в двух вариантах: с союзным словом "который" и причастным оборотом. Модель: Нефть - это горючая маслянистая жидкость со своеобразным запахом и цветом. Цвет нефти меняется в зависимости от состава от тёмно-бурого до светложёлтого. $\rightarrow$ a) Нефть - это горючая маслянистая жидкость со своеобразным запахом и цветом, который меняется в зависимости от состава от тёмно-бурого до светло-жёлтого. б) Нефть это горючая маслянистая жидкость со своеобразным запахом и цветом, меняющимся в зависимости от состава от тёмно-бурого до светло-жёлтого.

II.1. Образуйте деепричастия от данных глаголов по моделям: НCB: изучать $\rightarrow$ изучают $\rightarrow$ изучая, строить $\rightarrow$ строят $\rightarrow$ строя; заниматься $\rightarrow$ занимаются $\rightarrow$ занимаясь; СВ: изучить $\rightarrow$ изучив, встретиться $\rightarrow$ встретившись; составьте с образованными деепричастиями СС (или ПП), типа: Ученый , изучая данное явление, делал пометки в тетради. Ученый, изучив данное явление, сделал ряд заявлений для прессы.

II.2. Вставьте вместо точек деепричастия нужного вида, образовав его от одного из глаголов, данных в скобках. Объясните свой выбор. Модель: Журнал "Наука и жизнь" 
продолжает выходить каждый месяц, ....(осmaваmься - остаться) уже на протяжении десятилетий одним из самых востребованных научно-популярных журналов в России. $\rightarrow$ Журнал "Наука и жизнь" продолжает выходить каждый месяц, оставаясь уже на протяжении десятилетий одним из самых востребованных научно-популярных журналов в России.

II.3. Определите значение деепричастного оборота. Замените его на СПП $c$ придаточным. Приведите все возможные варианты. Модель: Окончив химикотехнологический факультет, Фуад начал работать на Сангачальском терминале. $\rightarrow$ a) Когда Фуад окончил химико-технологический факультет, он начал работать на Сангачальском терминале. б) Фуад окончил химико-технологический факультет, поэтому он начал работать на Сангачальском терминале. в) Фуад начал работать на Сангачальском терминале, потому что он окончил химико-технологический факультет.

Изучая лексико-грамматические темы курса "Научный стиль речи": (а) способы определения и классификации предметов и явлений природы; (б) способы выражения предмета и задач изучения, предмета исследования и наблюдения; (в) способы выражения соотношения части и целого, состава предмета; (г) способы выражения существования, наличия и отсутствия явления; (д) способы характеристики веществ по составу и свойствам; (е) способы указания на изменение веществ и их состояния; (ж) способы получения, применения, использования предмета, явления; (3) способы выражения умозаключения, вывода; (и) способы выражения отношения субъекта к научному объекту наблюдения, исследования [6] - необходимо уделять внимание не только реализации лексико-грамматических категорий в тексте научного содержания, но и таким важным средствам оформления предложений, как порядок слов, актуальное членение предложения, логическое ударение. Особо хочется остановиться на порядке слов в предложении.

В китайском языке (далее - КЯ) слово не имеет внешних морфологических показателей, поэтому в зависимости от положения в предложении оно может изменять свои первоначальные функции. Так, например, в китайском предложении на первом месте обычно располагается подлежащее (в русском же языке - далее РЯ - такой обязательности не наблюдается), затем следует сказуемое, выраженное глаголом, (в РЯ сказуемое может занимать любое место в предложении и быть выражено не только глаголом). В КЯ определяемое слов (кроме приложения) всегда располагается перед определяемым, в то время как в РЯ согласованное определение может стоять перед определяемым, или как несогласованное определение, может располагаться после определяемого. В КЯ определение в постпозиции к подлежащему становится сказуемым. Такая позиция встречается и в РЯ. В КЯ обычное место для прямого дополнения - после сказуемого, но с помощью служебных слов инверсированное прямое дополнение может находиться и в самом начале предложения или перед глаголом. В РЯ дополнение (прямое или косвенное) может занимать любое место.

Флективность русского языка сужает грамматическую функцию порядка слов, и наоборот, отсутствие форм словоизменений делает более важной функцию порядка слов в китайском. И поэтому грамматическая функция порядка слов в РЯ представлена менее ярко по сравнению с китайским языком. [3] А отсюда следуют закономерные ошибки в речи китайских студентов. Как-то:

1. Неумение строить предложение с расположением подлежащего в конце предложения.

2. Сказуемое неверно ставится в конце русского предложения (как в КЯ).

3. Неверно расставляются обстоятельства времени и места, так как в отличие от РЯ, где обстоятельство находится в начале или в конце предложения, в КЯ обычное место для обстоятельства времени и места - после подлежащего и перед сказуемым. Если в одном предложении имеются одновременно обстоятельства времени и места, тогда первое стоит перед вторым. В связи с этим было обнаружено, что под воздействием китайской грамматики студенты в своих работах на русском языке оба обстоятельства ставят или в начале предложения, или перед сказуемым (в контактной препозиции как семантически весомого члена предложения)

4. Неправильно располагаются обстоятельства образа действия, потому что они в РЯ обычно примыкают к глаголу, к которому относятся. В КЯ обстоятельство образа действия обычно стоит перед сказуемым, кроме случая, когда обстоятельство образа действия выражено наречием.

5. Неумение определить место наречия в русском предложении, так как в РЯ наречие может стоять перед глаголом и после него, а в КЯ - после глагола.

6. Неправильный порядок следования относительного и качественного прилагательного, т.к. в КЯ относительное прилагательное стоит перед качественным. 
7. Постановка несогласованного определения перед определяемым словом, потому что в КЯ не существует понятий несогласованное/согласованное определение.

8. Приложение неверно ставится перед определяемым именем существительным, так как в КЯ уточняющее приложение обычно ставится перед определяемым именем существительным.

Проблема порядка следования слов в русском предложении становится еще более актуальной в свете ошибок, допускаемых при построении СПП с различными типами придаточных.

В курсе "Научный стиль речи" следует обратить особое внимание на способы выражения и оформления (союзы, союзные слова, предлоги и др.) причинно-следственных, целевых, условных, временных, а также уступительных, сравнительных отношений в СПП и сопоставительных, противительных отношений в ССП. На конкретных примерах следует разобрать особенности следования частей (главной и придаточной части, включение придаточной в состав главной, наличие несколько типов придаточных, типы синтаксической связи придаточных и главной частей) в СПП. Здесь мы хотели бы привести несколько типов заданий, связанных с трансформацией ПП в СПП и одного типа СПП в другой:

1. Замените ПП с обстоятельством цели на СПП с придаточным иели. Модель: Для изучения роста амплитуды структуры во времени строят графики роста поднятия локальных структур. $\rightarrow$ Чтобы изучить рост амплитуды структуры во времени, строят графики роста поднятия локальных структур.

2. Информацию передайте с помощью СПП с придаточными условными (а) и времени (б). Модель: При увеличении давления нефть сжимается. $\rightarrow$ (а) Нефть сжимается, если увеличивать давление. Если увеличивать давление, то нефть сжимается. (б) Когда увеличивают давление (Когда увеличивается давление), нефть сжимается.

3. Замените СПП с придаточным условия на ПП (конструкция: При + сущ. 6.П.п.) Модель: Если рельеф местности неровный, то планируют площадку. $\rightarrow$ При неровности рельефа местности планируют площадку.

4. Из двух ПП составьте (а) СПП с придаточнылм причины, (б) СПП с придаточным иели, (в) СПП с придаточным условия. Модель: Нефть нагревают. Легкие фракции испаряются. $\rightarrow$ (а) Легкие фракции испаряются, потому что нефть нагревают. (б) Нефть нагревают, чтобы легкие фракции испарялись. (в) Если нагревают нефть, легкие фракции испаряются.

Выводы. Итак, мы рассмотрели особенности лексико-грамматического строя языка специальности инженеров-специалистов в области нефти, газа и химии и трудности освоения его китайскими учащимися начального этапа обучения. Мы провели сравнительный структурносемантический анализ эквивалентных конструкций русского и китайского языков, определили причины возникновения ошибок у китайских студентов, обучающихся на русском языке, предложили типы заданий, направленных на устранения погрешностей в речи студентов-иностранцев.

Предлагаемый в статье дидактический материал и методические рекомендации, как нам кажется, будут полезны преподавателям при подготовке иностранных студентов к чтению и восприятию учебной литературы. Они будут способствовать развитию коммуникативных навыков студентов и более активному участию последних в практических занятиях и в практике самоподготовки по избранной специальности.

\section{ЛИТЕРАТУРА}

1. Беляева, Е. В. (2004) Когнитивные механизмы возникновения речевых ошибок при усвоении русского языка в иноязычной аудитории. Автореф. канд.дис., Красноярск, - Диссертации по гуманитарным наукам - http://cheloveknauka.com/kognitivnye-mehanizmy-vozniknoveniya-rechevyh-oshibok-pri-usvoeniirusskogo-yazyka-v-inoyazychnoy-auditorii\#ixzz 3MQhopqDb

2. Васильева, Т.В. (2012). Информатика. Книга для преподавателя: учебное пособие по языку специальности. (Читаем тексты по специальности, Вып. 12) (1-ое изд.) М.: Златоуст, 18-19.

3. Гао Синь. Порядок слов в русском языке в зеркале китайского языка. Диссертации по гуманитарным наукам http://cheloveknauka.com/poryadok-slov-v-russkom-yazyke-v-zerkale-kitayskogo-yazyka\#ixzz3MLzSjiaW

4. Горелов, В.И. (1982). Грамматика китайского языка. (2-ое изд.) М.: Просвещение, 280.

5. Лю Ди. (2014). Русское деепричастие как единица перевода: грамматические, семантические и прагматические аспекты перевода на китайский язык. Дис. на степень канд.филол.наук. - М.: МГУ.196 - esti.msu.ru/netcat_files/2308_106.pd

6. Мусабекова, Н.Ч. (2014). Пособие по научному стилю речи для студентов-иностранцев подготовительного факультета (инженерно-технический профиль обучения). Книга для студента. Баку: АзТУ.105. 